\title{
Quantifying spatial scaling patterns and their local and regional correlates in headwater streams: implications for resilience
}

\author{
Emma Göthe $^{1}$, Leonard Sandin $^{2}$, Craig R. Allen $^{3}$ and David G. Angeler $^{2}$
}

\begin{abstract}
The distribution of functional traits within and across spatiotemporal scales has been used to quantify and infer the relative resilience across ecosystems. We use explicit spatial modeling to evaluate within- and cross-scale redundancy in headwater streams, an ecosystem type with a hierarchical and dendritic network structure. We assessed the cross-scale distribution of functional feeding groups of benthic invertebrates in Swedish headwater streams during two seasons. We evaluated functional metrics, i.e., Shannon diversity, richness, and evenness, and the degree of redundancy within and across modeled spatial scales for individual feeding groups. We also estimated the correlates of environmental versus spatial factors of both functional composition and the taxonomic composition of functional groups for each spatial scale identified. Measures of functional diversity and within-scale redundancy of functions were similar during both seasons, but both within- and cross-scale redundancy were low. This apparent low redundancy was partly attributable to a few dominant taxa explaining the spatial models. However, rare taxa with stochastic spatial distributions might provide additional information and should therefore be considered explicitly for complementing future resilience assessments. Otherwise, resilience may be underestimated. Finally, both environmental and spatial factors correlated with the scale-specific functional and taxonomic composition. This finding suggests that resilience in stream networks emerges as a function of not only local conditions but also regional factors such as habitat connectivity and invertebrate dispersal.
\end{abstract}

Key Words: biodiversity; cross-scale resilience; functional feeding groups; invertebrates; local and regional determinants; river ecosystems; spatial modeling

\section{INTRODUCTION}

Ecological resilience is most simply defined as the amount of disturbance a system can tolerate and its capacity to reorganize before it is pushed to a different stable state, i.e., into a different domain of attraction, thereby losing its original functions and processes (Holling 1973). An assessment of ecological resilience in different ecosystems worldwide is important because ongoing global change causes rapid declines in species diversity (e.g., Heywood 1995, Sala et al. 2000), which may erode resilience, cause undesired regime shifts, and affect ecosystem functions that sustain important ecosystem services for humanity (Ehrlich and Ehrlich 1981, Chapin et al. 2000, Balvanera et al. 2006).

Several measures have been suggested to indicate ecosystem resilience, e.g., response diversity (Elmqvist et al. 2003) and functional redundancy (Allen et al. 2005). We focus on functional redundancy, i.e., the number of species performing the same function in an ecosystem, which indicates how many species can be lost without jeopardizing processes in ecosystems (e.g., Luck et al. 2003). However, the importance of functional redundancy within a community for ecosystem resilience cannot be understood without considering the hierarchical organization of ecosystems (Allen et al. 2014). That is, ecological patterns manifest, and processes unfold, at independent scales of space and time (Holling 1992, Nash et al. 2014). For example, because organisms of different sizes differ in their resource use as a function of the spatial and temporal distribution of these resources, distinct scales at which different organisms operate can be distinguished. Because there are limited numbers of structuring processes in a system, there are limited numbers of scales, and functionally redundant species may exist both within and across these scales. Therefore, researchers have developed the cross-scale resilience model (Peterson et al. 1998) that accounts for both the scale-specific hierarchical structure of ecosystems, i.e., nested levels of structuring variables and processes, and the distribution and redundancies of functional traits within and across those scales. In turn, resilience in ecological communities can be assessed empirically (Peterson et al. 1998).

Methods have been developed to assess the scaling structure in ecological systems objectively (Stow et al. 2007). For instance, many studies have determined the number of scales, as well as the species and their functional traits associated with each scale, by studying discontinuities in body mass distributions in animals (Allen and Holling 2008). Others have used time series modeling to identify scales of fluctuation frequencies based on abundance and biomass data (Angeler et al. 2011, 2013a). However, the cross-scale resilience model, i.e., within- and cross-scale functional redundancy, has been tested with limited data for a few terrestrial (Forys and Allen 2002, Allen et al. 2005, Fischer et al. 2007) and aquatic ecosystems (Angeler et al. 2013a,b). No assessments are yet available from streams.

In contrast to ecosystems with clearly defined boundaries, e.g., lakes, islands, and forest patches, stream networks have a hierarchical and linear, i.e., dendritic, structure without clearly defined patch boundaries along the watercourses. The unique spatial structure of stream networks therefore needs to be accounted for when assessing the scaling structure of these ecosystems. We use explicit spatial modeling to identify spatial scales of distributions of benthic invertebrates based on their abundances in the stream network. We then assess the distribution of functional feeding groups within and across modeled spatial scales and evaluate the resilience of streams following the cross-scale resilience model. 
Benthic invertebrates are key organisms in streams that play important roles in multiple ecosystem processes, including secondary production, leaf litter processing, nutrient cycling, and matter and energy fluxes (Merritt and Cummins 1996, Wallace and Webster 1996). Assembly of invertebrate communities depends on not only environmental factors at the local patch scale, i.e., water flow and chemistry, but also regional factors, i.e., interpatch connectivity and dispersal (Brown and Swan 2010, Erős et al. 2012, Göthe et al. 2013, Heino 2013). This makes invertebrates ideal candidates for assessing the relevance of both local environmental and regional processes on the distribution of functions at different spatial scales. However, explicit consideration of regional factors in empirical testing of resilience is so far lagging, although the importance of such factors has been recognized (Nyström and Folke 2001, Cumming 2011).

Streams are adapted to strong natural variability associated with hydrologic disturbance regimes (Resh et al. 1988, Townsend 1989). These fluctuations vary with season and are manifested in considerable abiotic, e.g., hydrology, water chemistry, temperature, and availability in food resources (Giller and Malmqvist 1998, Laudon and Bishop 1999, Laudon et al. 2004), and biotic, i.e., species turnover (Cowell et al. 2004, Bogan and Lytle 2007), variability. However, despite species turnover in time, overall changes in functional community structure do not necessarily happen, highlighting functional stability (e.g., Petersen et al. 1999). From a resilience perspective, the ecological conditions inherent to streams suggest that these systems operate in a broad basin of attraction. If this is the case, it follows that (1) the number of scales found and functional redundancy within and across those scales will be similar between seasons, and (2) within- and cross-scale redundancies of functional traits will be high to accommodate persistence of community structure and function on seasonal and interannual scales in streams. Using invertebrate, environmental, and spatial data collected from a boreal Swedish headwater catchment, we aim to evaluate (1) functional redundancy within and across spatial scales related to the distribution of invertebrate species in the stream network during two different seasons and (2) the relative importance of environmental and spatial factors structuring the scale-specific distribution of invertebrates and their associated functional traits in the catchment.

\section{MATERIALS AND METHODS}

\section{Study site}

We selected the Krycklan River catchment, situated in northern Sweden, county of Västerbotten, for study (Fig. 1). Coniferous forests and wetlands dominate the catchment (Buffam et al. 2007). The annual mean temperature is $1^{\circ} \mathrm{C}$, and annual mean precipitation is $\sim 600 \mathrm{~mm}$, i.e., one-third of the precipitation falls as snow (Ottosson Löfvenius et al. 2003). We sampled benthic invertebrates and measured a number of local environmental factors at 52 sites, i.e., first- to third-order stream reaches. Sampling was performed along a 30-m stretch at each site in May and October 2009. The sampling in May was done directly after a spring flood, whereas the sampling in October was done after a longer period of base-flow conditions. Hydrologic conditions at the time of our sampling were assessed by plotting daily discharge measurements from 1 sampling point in the catchment (H. Laudon, unpublished data).
Fig. 1. Location of the Krycklan catchment in Sweden (top right) and location of the 52 sampling sites within the catchment.

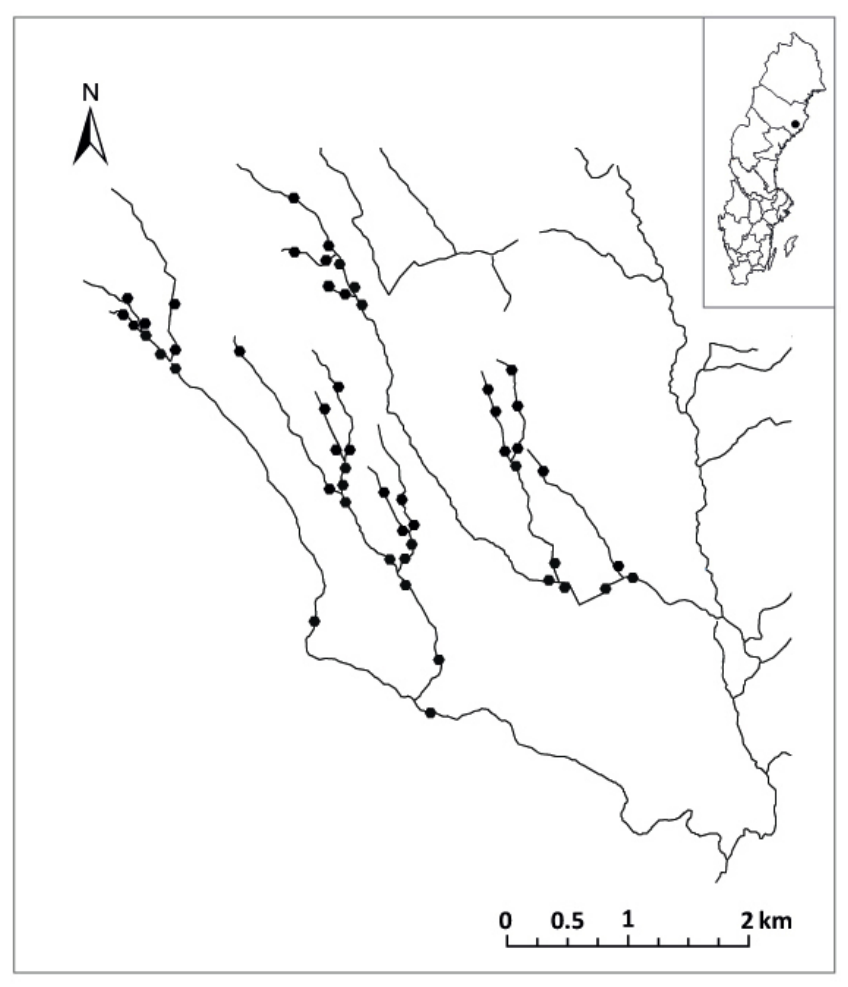

Benthic invertebrate sampling

We used a Surber sampler (frame size: $14 \times 14 \mathrm{~cm}$; mesh size: $500 \mu \mathrm{m})$ to sample the invertebrates along the $30-\mathrm{m}$ stretch. In total, 9 Surber samples, total sample area of $\sim 0.18 \mathrm{~m}^{2}$, were collected at each site. The samples were preserved in $70 \%$ ethanol and brought back to the laboratory for sorting and identification. The benthic invertebrates were identified to the lowest possible taxonomic level, in most cases to species or genus. However, some groups were identified to a higher taxonomic level, e.g., Simuliidae and Coleoptera, which were identified to family level, and Chironomidae, which was identified to the subfamily level. Invertebrates were then divided into functional feeding groups, i.e., scrapers, filterer collectors, gatherer collectors, predators, and shredders (Moog 1995, Merritt and Cummins 1996).

\section{Habitat characterization and water chemistry sampling}

We measured stream width, depth, flow, and canopy cover every $5 \mathrm{~m}$ along the $30-\mathrm{m}$ stretch. Depth and flow were measured at 3 points on each transect, from each channel edge, i.e., at approximately one-fourth of the channel width, and from the middle of the stream. Stream width and canopy cover were measured once at each transect. We estimated canopy cover by taking digital photographs from the middle of the stream at the surface pointing upward toward the canopy. By using the computer software Image-Tools (Health Science Center, University of Texas, San Antonio, Texas, USA), images were 
manipulated so that black pixels represented the canopy and white pixels represented open areas. The mean canopy cover at each site was then assessed by calculating the mean percentage of black pixels per image and site. A pebble count method (Wolman 1954) was used to estimate substratum composition. At each site, 100 stones were randomly picked up and measured. The pebble count data were then divided into 8 different substratum classes based on the size of the particles, after which the percentage of each substratum class could be calculated. In conjunction with the pebble count procedure, we also estimated moss cover by noting the presence/absence of moss on each of the 100 substrate pebble samples. The amount of dead wood at each site was estimated by counting the number of branches and $\operatorname{logs}$ that measured $>1 \mathrm{~cm}$ in diameter in the stream channel. Water chemistry samples were taken and analyzed for major anions and cations, metals $(\mathrm{Fe}, \mathrm{Al}), \mathrm{pH}$, nutrients (total $\mathrm{N}$, total $\mathrm{P}, \mathrm{NO}_{2}+\mathrm{NO}_{3}$ ), water color (absorbance at $420 \mathrm{~nm}$ ), total organic carbon, and carbon dioxide $\left(\mathrm{CO}_{2}\right)$. A drought inventory was performed on 2 occasions during the warmest period of the summer, i.e., late June and early July, because a characteristic of the Krycklan catchment, and headwater catchments in general, is that some upstream sites are intermittent, i.e., they dry out during the summer months. Thus, coordinates were used to mark the point above which the stream was dry or only consisted of scattered pools without any permanent water flow, and sites were classified as affected/not affected by drought. Land use was assessed from digital maps, i.e., shape files acquired from the Swedish forestry agency and the Swedish Land Survey, and calculated for the catchment area upstream of each sampled site in ArcGIS, version 9.3.1 (ESRI, Redlands, California, USA).

\section{Data analyses}

Data analyses focused on identifying the spatial scales at which groups of invertebrate taxa are distributed, following the spatial modeling framework of Borcard and Legendre (2002) and Borcard et al. (2004). Spatial modeling allows extracting scaling structure that is inherent in the data, avoiding bias that can arise when researchers define scales arbitrarily. After the identification of spatial scales, we identified taxa or taxonomic groups associated with each spatial scale, followed by calculation of functional diversity indices and estimates of within- and crossscale redundancy in the catchment. Finally, we disentangled environmental versus spatial control of functional composition and taxonomic composition within functional groups, i.e., redundancy, at each spatial scale. Methodological details follow. All statistical analyses were carried out in $\mathrm{R}$ version 2.13 .2 ( $\mathrm{R}$ Development Core Team 2011).

\section{Identification of spatial scales and taxa associated with each spatial scale}

To identify spatial scales in our data, we employed principal coordinates of neighbor matrices analysis, or PCNM (Borcard and Legendre 2002, Borcard et al. 2004), through the function quickPCNM in the R package PCNM (Legendre et al. 2010). PCNM is a spatial modeling technique based on redundancy analysis (RDA), which breaks down the overall spatial structure of communities into independent spatial structures. That is, the analysis collapses patterns of groups of species with similar spatial distribution and abundance patterns into independent RDA axes, so that the spatial pattern of species associated with one axis is significantly different from spatial patterns associated with other axes. For instance, in a stream, some species may show broadscale spatial patterns that capture the longitudinal gradient from headwaters to lowland sections of the network. Other species might show variability at finer spatial scales, e.g., between-patch variability. Because RDA axes are orthogonal, they are suitable for modeling spatial structure at independent scales (Borcard and Legendre 2002). However, the capacity to model structure at coarse versus fine spatial grains depends on the extent of area covered and the spatial resolution of sampling points within the area.

Species are often absent from sites, resulting in many zeros in species matrices. Data transformations are therefore required to make species data suitable for analysis with multivariate, linear, Euclidean-distance-based methods, e.g., RDA (Legendre and Gallagher 2001). We therefore carried out Hellinger transformation of the species data prior to analysis; this transformation is achieved by dividing the species abundances by the row sum and taking the square root of the resulting values (Legendre and Gallagher 2001). The principles of PCNM and how we used this framework to identify the spatial scales shown by the invertebrates in the Krycklan catchment can be described in the following four steps:

1. A number of spatial variables (PCNMs) were first created based on geographic $x, y$-coordinates of the sampling sites. The PCNMs were obtained though principal coordinate analysis of a truncated geographic distance matrix among the sites and describe all possible spatial scales that can be accommodated in the sampling design. PCNMs with high eigenvalues, i.e., low-order PCNMs, represent broadscale spatial structures in species distribution; whereas PCNMs with low eigenvalues, i.e., high-order PCNMs, represent small-scale spatial structures (Borcard and Legendre 2002, Borcard et al. 2004).

2. The PCNMs were then related to the species abundance data by means of RDA, and significant PCNMs, representing nonrandom spatial structures in species distributions and their abundances across the sampling sites, were selected through a forward selection procedure.

3. Significant PCNMs were then linearly combined in one RDA model to extract spatial structures in the communities at different spatial scales. The significance of each RDA axis was tested by means of permutation tests. Each significant RDA axis $(\mathrm{p}<0.05)$ can be interpreted as an independent spatial scale at which a subset of species is structured. Thus, the number of significant RDA axes in the model equals the number of spatial scales in the ecosystem, based on species distributions and abundances.

4. To identify the invertebrate taxa associated with each of these spatial scales, i.e., significant RDA axes, abundance data of each taxon were correlated with the site (linear combination) scores of each significant RDA axis. Taxa that correlated significantly $(\mathrm{p}<0.05)$ with the site-scores of each axis were considered to be representatives of that particular scale (Angeler and Johnson 2012) and thus retained for further analyses of functional characteristics. 
Estimating functional diversity and redundancy within and across spatial scales

Based on the analysis that identified the taxa that correlated significantly with the canonical axes, i.e., spatial scale, during both seasons, we calculated three estimates of functional diversity, i.e., Shannon index, evenness, richness, in the computer software PAST (Hammer et al. 2001). As measures of within-scale redundancy, we calculated (1) the mean number of taxa per functional group, averaged across sites and spatial scales, and (2) an index based on mean distances between sites in multivariate space within spatial scales. Cross-scale redundancy was estimated by calculating mean distances in multivariate space between spatial scales. The distances, i.e., indices of within- and cross-scale redundancy, were calculated based on functional composition data that were transformed into Bray-Curtis dissimilarities. Thus, they provide an estimate of overlap in functional composition and can be used as a simple and straightforward index of redundancy. That is, low average distances within or between spatial scales implies larger overlap in functional structure and thus higher redundancy. Mean distances within and between spatial scales were calculated using the function meandist in $\mathrm{R}$ package vegan (Oksanen et al. 2013) and visualized with a nonmetric multidimensional scaling diagram obtained through the function metaMDS in R package vegan.

Note that our measures of within- and cross-scale redundancy differ from others used in previous research (e.g., Allen et al. 2005). Previously, the average number of species per functional group has been used as a measure of within-scale redundancy, whereas cross-scale redundancy has been assessed by noting the presence or absence of a functional group across scales (Allen et al. 2005). We extend our assessment of redundancy by using a multivariate approach based on measures of functional similarity between sites within or across scales. We suggest that an assessment of within- and cross-scale redundancy benefits from such an approach because it allows us to assess the similarity of functional composition across scales based on both functional identity and abundance. Because resilience is likely dependent both on (1) the redundancy of individuals within populations and functional groups, i.e., species abundances, and (2) the redundancy of species within functional groups, i.e., richness, we believe this approach is a more comprehensive way of assessing redundancy.

Seasonal differences of measures of functional redundancy were assessed using ANOVA (type III) because of unequal sample sizes (Shaw and Mitchell-Olds 1993). These tests were performed with the function anova in R package car (Fox and Weisberg 2011). Because the spatial scales identified are associated with orthogonal, i.e., independent, RDA axes, we considered each scale as an independent replicate in the analysis. However, because sample size was low, i.e., two spatial scales in spring and three in autumn, our aims were to assess trends of pattern rather than a quantification of the pattern per se.

\section{Environmental versus spatial correlates of functional and} taxonomic composition

Hellinger-transformed abundance data of functional composition, i.e., diversity, and taxonomic composition within functional groups, i.e., redundancy, at each spatial scale were used as response matrices. Environmental data, i.e., water chemistry, hydromorphology, and land use, and spatial variables obtained from PCNM analyses (see previous discussion) were used as predictors. Environmental variables were log or square-root transformed where necessary to approximate normal distributions. We also performed a centered log ratio transformation on the land-use and substratum composition data as it creates linearity in the data and solves the problem of compositional data that sum to unit one (Aitchison 1983, Wang et al. 2010). Then, a forward selection procedure was performed on the environmental and spatial predictors with the function forward.sel in R package packfor (Dray et al. 2009). This analysis allowed us to retain variables significantly $(\mathrm{p}<0.05)$ related to functional composition or taxonomic composition within each functional group at each spatial scale. Significant environmental and spatial variables were then used in a variance partitioning analysis, which was performed with the function varpart in $\mathrm{R}$ package vegan (Oksanen et al. 2013). The variance partitioning analyses allowed us to calculate fractions of functional and taxonomic composition explained uniquely by environmental and spatial predictor matrices through partial redundancy analyses. Combined fractions explained by the two predictor matrices and unexplained fractions were also calculated. The significance of unique fractions explained was estimated with the function rda in $\mathrm{R}$ package vegan (Oksanen et al. 2013). For some scales and functional groups, only one taxon was present. However, the $\mathrm{R}$ functions described previously, i.e., forward.sel, varpart, and rda, work also with single response variables, but instead of RDA, the calculations are based on linear regression analysis.

\section{RESULTS}

\section{Functional metrics}

Our analyses identified groups of invertebrate taxa that were structured at 2 and 3 spatial scales in spring and autumn, respectively (Fig. 2a, b). The average overall functional diversity within each spatial scale in the system was generally low (Shannon index: spring mean $0.62 \pm$ standard error [SE] 0.06, autumn mean $0.77 \pm$ SE 0.09; functional richness: spring mean 2.6 \pm SE 0.2, autumn mean 3.1 \pm SE 0.4; functional evenness: spring mean 0.76 \pm SE 0.01, autumn mean $0.75 \pm$ SE 0.04). No significant differences in functional metrics were found between seasons ( $p$ $>0.05$ for all indexes).

\section{Within- and cross-scale functional redundancy}

The average functional redundancy, i.e., number of taxa belonging to a feeding group, within spatial scales was slightly higher in spring for shredders and filterer collectors (shredder: spring mean $1.7 \pm$ SE 0.9, autumn mean 1.2 \pm SE 0.5; filterer collector: spring mean $1.0 \pm$ SE 0.1, autumn mean 0.4 \pm SE 0.3), whereas it was slightly higher in autumn for predators and gatherer collectors (predator: spring mean $0.2 \pm$ SE 0.2, autumn mean 1.4 \pm SE 0.3; gatherer collector: spring mean 1.0 \pm SE 0.9, autumn mean 1.7 \pm SE 0.2). However, seasonal comparisons of within-scale redundancy were nonsignificant $(p>0.05)$. The mean number of taxa per functional group was $<2$, highlighting low redundancy. The multivariate, distance-based index of withinscale redundancy was slightly lower in autumn (mean $0.23 \pm \mathrm{SE}$ 0.03 ) compared with spring (mean $0.28 \pm \mathrm{SE} 0.01$ ) but did not differ significantly $(\mathrm{p}>0.05)$. 
Fig. 2. Eigenvector maps showing the spatial structures identified at each spatial scale (RDA axis) in (a) spring and (b) autumn. The squares in the maps are equivalent to the spatial location of each sampling site in the Krycklan catchment (as shown in Fig. 1). The color of the squares represents the sign of correlation (white, negative; black, positive), and the size of the squares is proportional to the site scores (numbers under the squares) indicating the strength of correlation.

\section{a)}

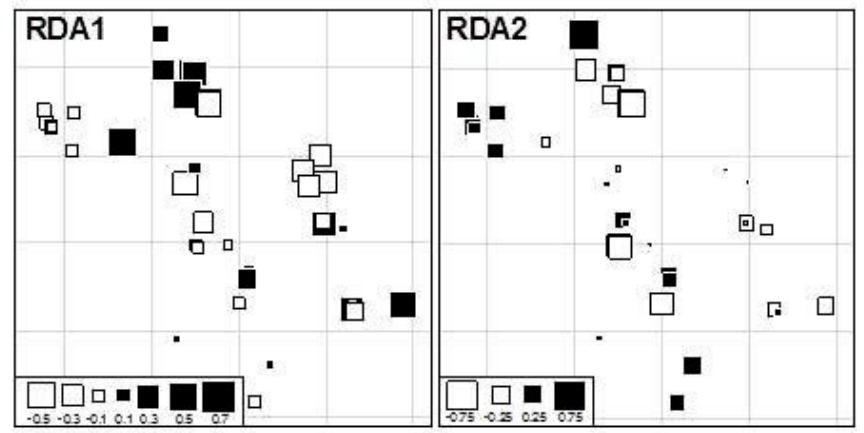

b)

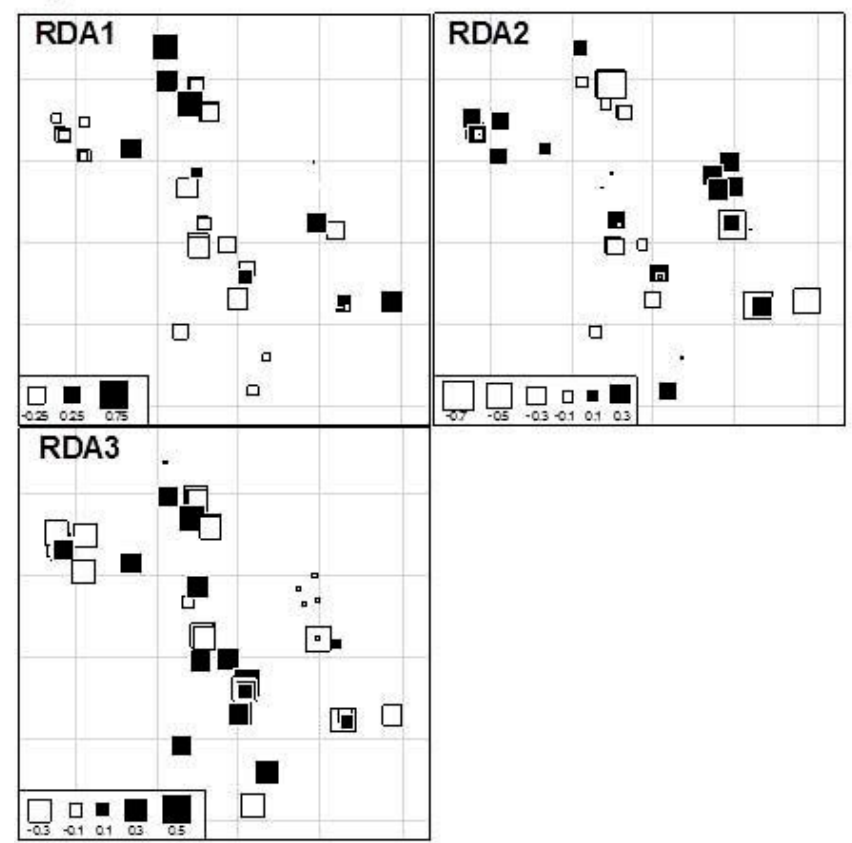

The multivariate, distance-based measure of cross-scale redundancy showed that cross-scale redundancy was higher in autumn, i.e., lower mean value indicating closer proximity in multivariate space $(0.46 \pm$ SE 0.05$)$, compared with spring (0.63). Differences in cross-scale redundancy could not be statistically evaluated because there was only 1 value in spring, i.e., 1 distance value between 2 spatial scales. The functional and taxonomic composition across scales and seasons shows overlap in functional but not taxonomic composition between seasons, e.g., functional composition of RDA2 in spring overlapped substantially with RDA1 in autumn (Fig. 3a, b).
Fig. 3. Nonmetric multidimensional scaling diagrams showing (a) taxonomic and (b) functional feeding group composition across and within the different spatial scales (RDA1, RDA2, RDA3) identified through principal coordinates of neighbor matrices analysis and between the two seasons (spring and autumn). The analysis is based on Bray-Curtis dissimilarities and $n=52$ in all defined groups.
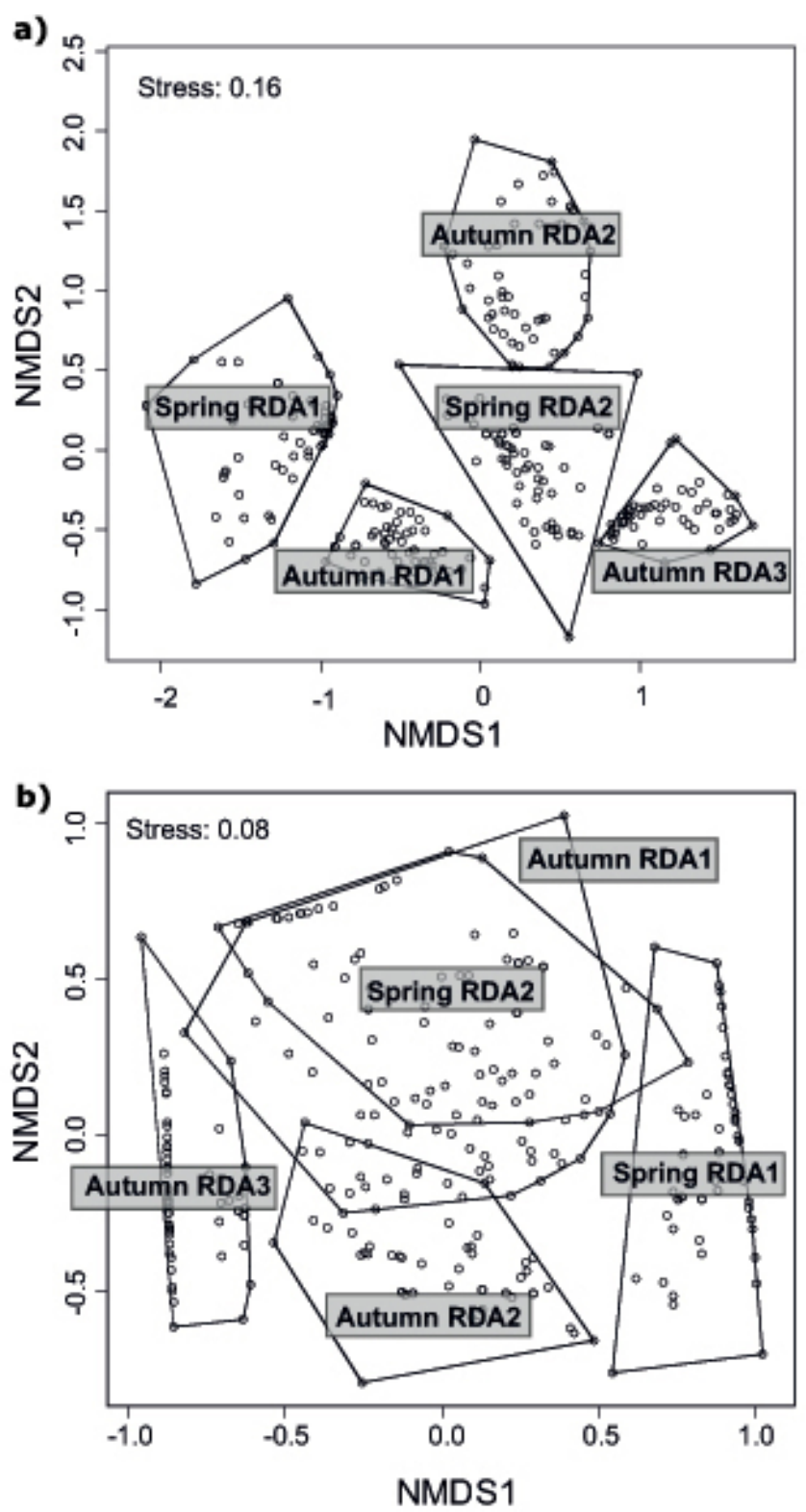

Spatial and environmental correlates of functional composition and redundancy

The variance partitioning analyses revealed that both environmental and spatial factors correlated with functional composition within each spatial scale and season. The variance uniquely and significantly explained by environmental and spatial factors ranged between $11-27 \%$ and $10-28 \%$, respectively, and the shared fraction, i.e., spatially structured environmental variation, 
Fig. 4. Results of the variance partitioning analyses. The figure shows the amount of variance in (a) functional composition and (b) taxonomic composition within each functional group explained (\%) by local environmental factors (E) and spatial eigenvectors (S). Shown are also variances explained jointly by environmental and spatial factors $(E \cap S)$ and unexplained variation $(U)$. X indicates that no taxa were associated with that particular scale and functional feeding group. F, filterer collector; GC, gatherer collector; P, predator; S, shredder. The tests are divided by season (spring and autumn) and spatial scale (RDA1, RDA2, and RDA3). The level of significance is indicated next to the bars (ns $\mathrm{p}>0.1, \cdot \mathrm{p}<0.1,{ }^{*} \mathrm{p}<0.05, * * \mathrm{p}<0.01$ ).

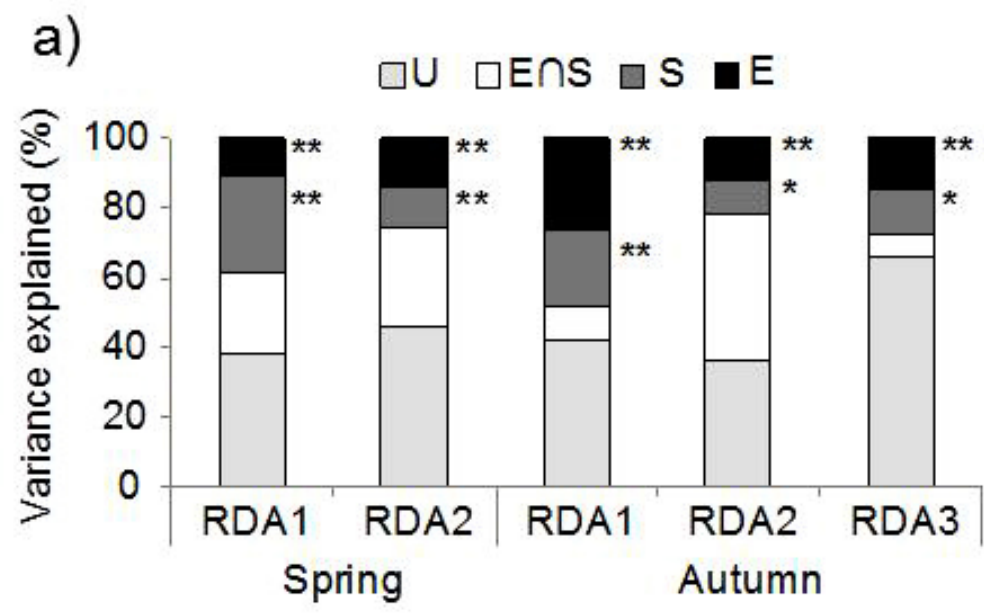

b)

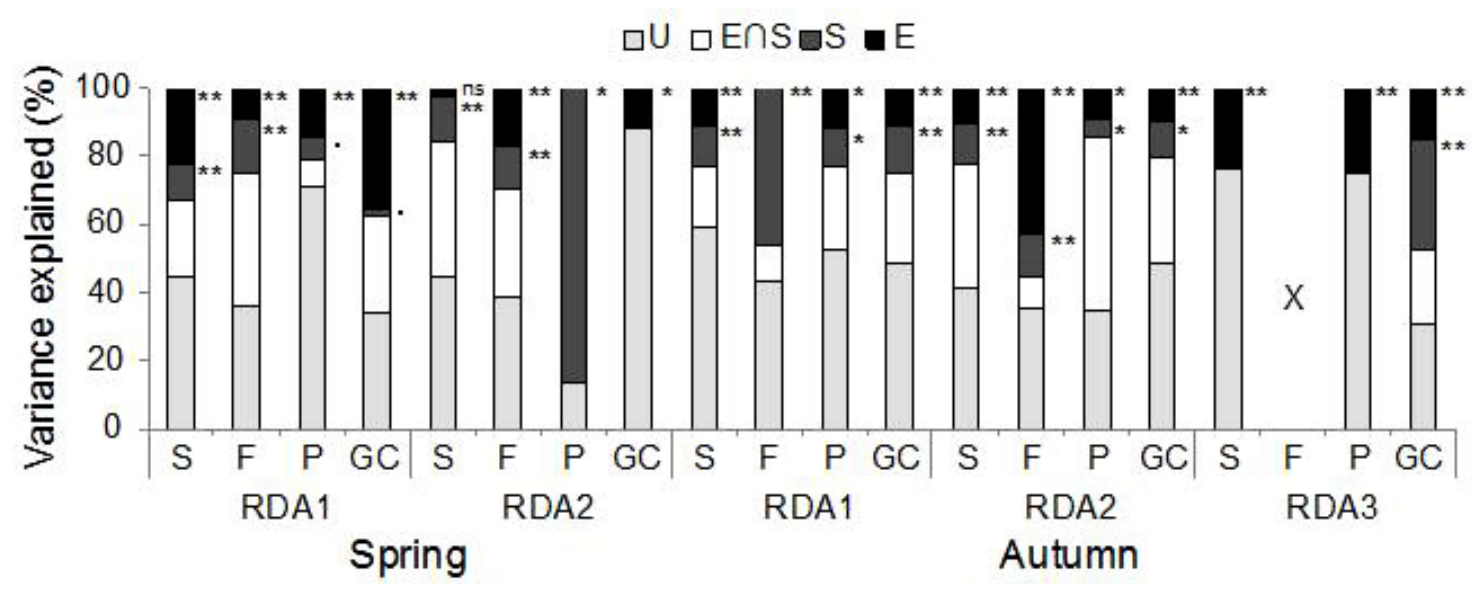

ranged between $7 \%$ and $42 \%$ (Fig. $4 \mathrm{a}$ ). The variance partitioning analyses of taxonomic composition within functional groups showed similar results where the majority of the analyses indicated both environmental and spatial control of taxonomic composition within each functional group and scale. However, 5 groups of taxa were related only to environmental variables, whereas 3 groups of taxa were related only to spatial variables (Fig. 4b).

\section{DISCUSSION}

We used a spatial modeling technique that has been commonly applied to infer scales of spatial structures in terrestrial (e.g., Lindo and Winchester 2009, Lu et al. 2011, Duarte et al. 2012) and aquatic (e.g., Landeiro et al. 2011, De Bie et al. 2012, Heino et al. 2012) environments. We used this technique to identify the number of spatial scales in a headwater stream network, based on the distribution and abundances of invertebrates. We extended the approach by quantifying the redundancy of functional feeding group characteristic of invertebrates within and across the spatial scales identified, allowing us to test the cross-scale resilience model (Peterson et al. 1998). Within- and cross-scale redundancies of functions within an ecosystem have been suggested to be important to assess the relative resilience of ecological and other complex systems (Peterson et al. 1998, Allen and Holling 2008, Garmestani et al. 2009).

Our spatially explicit approach also permitted an assessment of environmental versus spatial control of functional distribution 
within the scales identified. Although both environmental and spatial factors mediated functional distribution within each spatial scale, our results indicated low resilience of the stream network. This finding was unexpected but might be explained both with patterns of biodiversity that are inherent to headwater streams and our approach used to infer resilience.

Stream ecosystems show large environmental heterogeneity in space and over time (e.g., Frissell et al. 1986, Ward 1989, Montgomery 1999). One example of environmental heterogeneity in stream ecosystems is the change in environmental conditions that occur along the watercourses, leading to characteristic communities in upstream headwater areas and downstream sites. For example, substantial input of coarse organic matter, e.g., leaves, in upstream areas will benefit shredders; whereas poor conditions for algae growth, e.g., high shading and low temperatures, and low amounts of finer organic matter suspended in the water column will lead to lower abundances of scrapers, feeding on benthic algae, and filterer collectors, feeding on suspended material (Vannote et al. 1980, Richardson and Danehy 2007). Given the spatial segregation of resources in streams, functional feeding groups of consumer communities are patchy, and functional diversity can be expected to be relatively low in headwater streams. Indeed, functional diversity, i.e., Shannon index, richness, and evenness, in this catchment was low, not only in both seasons but also across the spatial scales present in the stream network.

Similarly, the within-scale redundancy for each functional feeding group was very low (mean $<2$ taxa). These results are not unexpected considering the ecosystem under study because the likelihood of functional loss, as well as the consequence of that loss, is expected to increase with decreasing species richness (Fonseca and Ganade 2001). That is, headwater streams are generally characterized by low alpha, but not necessarily low beta, diversity (Clarke et al. 2008, Finn et al. 2011) largely attributable to the strong environmental gradients across sites in upstream areas and their relatively isolated position in the river network. Isolation, preventing species from colonizing/recolonizing an area, in combination with strong environmental filters, preventing the establishment and maintenance of sensitive species and populations, is likely to lead to a weak scale-specific functional redundancy of these habitats. Also, recovery and reorganization after disturbances may be slow in headwater reaches in comparison with downstream reaches where the magnitude of dispersal, and thus colonization rates, can be considerably higher (Brown and Swan 2010, Brown et al. 2011).

Understanding how functions are distributed within and across scales of ecosystem organization is critical for understanding and assessing ecological resilience (Fischer et al. 2007, Wardwell et al. 2008, Sundstrom et al. 2012). The invertebrate community was structured at two and three spatial scales in spring and autumn, respectively. It can be expected that within- and cross-scale redundancy would be lower in spring because of stronger, but natural and continuously occurring, hydrologic disturbance; whereas autumn is characterized by more stable base-flow conditions. Although our results regarding within-scale redundancy did not support this expectation, there was one more significant spatial scale detected in autumn compared with spring, and the overlap in functional composition between spatial scales was higher in autumn compared with spring, i.e., indicating higher cross-scale redundancy (Fig. 3a, b). These results suggest that seasonal differences in cross-scale redundancy might be associated with hydrologic disturbance regimes in streams, but further research is required to scrutinize our finding.

The low number of spatial scales together with the low redundancy at each scale observed in our study system, i.e., less than or equal to half of what has been found in previous studies, may be viewed as an indication of a low within- and cross-scale reinforcement of functions in the stream network (Allen et al. 2005, Fischer et al. 2007) and, by extension, low resilience. Assuming weak resilience of streams is counterintuitive because communities in streams are adapted to high environmental variability and continuous hydrologic disturbance. That is, communities have evolved to cope with physical stress. In a resilience context, this suggests that streams operate in a broad basin of attraction, and within- and cross-scale redundancies are expected to be high to accommodate persistence of community structure and function on seasonal and interannual scales in streams.

We partly attribute our findings to the approach we used. Many studies have inferred functional redundancy within and across scales of ecosystem organization based on discontinuities in body mass distributions in, for instance, bird, mammal, and herpetofauna communities (Forys and Allen 2002, Fischer et al. 2007). We used explicit spatial modeling to infer the scale-specific distributions of species in the stream network based on their abundances. Because of the statistical nature of the approach, half of the taxa in our data set were excluded from the assessment of resilience because they were unrelated to the dominant spatial scales identified for each season. These taxa were rare and occurred only in too low abundances $(16 \%$ and $3 \%$ of the total abundance in spring and in autumn, respectively) to be associated with significant spatial patterns, thereby leading to stochastic noise. This is not surprising given that species distributions in streams are generally characterized by having a few dominant species and a relatively long tail of numerically rare species (Resh et al. 2005, Arscott et al. 2006, Siqueira et al. 2012). Focusing our evaluation on significant patterns only may therefore have resulted in a conservative estimate of resilience.

We acknowledge that in any assessment of resilience, numerically rare species can have a significant role (Angeler et al. 2013b, Baho et al. 2014). For instance, if abundant members of the same functional group are especially vulnerable to a particular disturbance, rare species with stochastic dynamics can potentially compensate for that loss and sustain important functions (Walker et al. 1999). The importance of rare species is easy to overlook because the strength of ecological function is often related to dominant species. However, a system's ability to absorb novel perturbations, i.e., its adaptive capacity, may reside as much in the identity of its rare species as in the within- and across-scale distribution of function of common species. The spatial modeling approach we used serves as a promising tool to quantify aspects of resilience in a spatially explicit way by scrutinizing both deterministic, i.e., within- and cross-scale structure, and stochastic patterns; quantifying the latter can provide additional information and complement future resilience assessments. We also acknowledge that any assessment of resilience can be refined 
by accounting for response diversity. This was not possible for us because of lack of data describing invertebrate response traits.

In addition to the exclusion of rare taxa in our assessment, we suggest two other explanations for the relatively low number of spatial scales and apparent low redundancy in our study system. First, the importance of spatial factors shaping ecological communities is expected to increase with spatial extent (e.g., Mykrä et al. 2007, Declerck et al. 2011). Because the size of the Krycklan stream network is small (study area extent: $\sim 20 \mathrm{~km}^{2}$ ), we may not have captured significant ecological scales, i.e., spatial patterns, that extend beyond our scale of observation. It is likely that cross-scale redundancy also occurs at these larger scales and that we have underestimated the actual cross-scale reinforcement present in this system, which consists of additional stream networks. Second, differences in spatial structuring between species within the aquatic invertebrate community may simply not be as pronounced as, for example, between species within terrestrial bird, mammal, and herpetofauna communities (Forys and Allen 2002, Fischer et al. 2007).

We conclude with highlighting the importance of considering both environmentally deterministic and spatial processes when assessing resilience. Functional composition and taxonomic composition within functional feeding groups was related to factors in both our study and others (Erős et al. 2012, Göthe et al. 2013). This suggests that a management approach focusing on restoring and conserving both landscape features and local habitat conditions is necessary to preserve functional diversity and redundancy of headwater catchments (Göthe et al. 2013). Connectivity and the capacity of organisms to disperse are important aspects mediating resilience at the landscape scale (Nyström and Folke 2001). Effective conservation and management of habitats in a landscape context therefore requires both local and regional approaches (Bengtsson 2010). We show how the relative importance of local and regional factors can be quantified and incorporated in managing landscapes to maintain resilience in the face of environmental change.

Responses to this article can be read online at: http://www.ecologyandsociety.org/issues/responses. $\mathrm{php} / 6750$

\footnotetext{
Acknowledgments:

We thank Lars Eriksson and Dan Evander for their help with the taxonomy, Peter Carlson for his assistance during fieldwork, Leif Göthe for providing both GIS support and assistance in the field, and the reviewers and editors of Ecology and Society for helpful comments. We also thank Hjalmar Laudon, Peder Blomqvist, and Viktor Sjöblom for their guidance and help in the field. Financial support of the August T. Larsson foundation of the Faculty of Natural Resources (Swedish University of Agricultural Sciences) and the USGS Powell Center for Analysis and Synthesis is gratefully acknowledged. Leonard Sandin was financed through the FRESHCLIM project (project no. 273215) from the Marie Curie Actions of the European Commission (FP7-2010PEOPLE-IEF). The Nebraska Cooperative Fish and Wildlife Research Unit is jointly supported by a cooperative agreement
}

between the U.S. Geological Survey, the Nebraska Game and Parks Commission, the University of Nebraska-Lincoln, the U. S. Fish and Wildlife Service, and the Wildlife Management Institute. Any use of trade names is for descriptive purposes only and does not imply endorsement by the U.S. government.

\section{LITERATURE CITED}

Aitchison, J. 1983. Principal component analysis of compositional data. Biometrika 70:57-65. http://dx.doi. org/10.1093/biomet/70.1.57

Allen, C. R., D. G. Angeler, A. S. Garmestani, L. H. Gunderson, and C. S. Holling. 2014. Panarchy: theory and applications. Ecosystems 17:578-589. http://dx.doi.org/10.1007/s10021-013-9744-2

Allen, C. R., L. Gunderson, and A. R. Johnson. 2005. The use of discontinuities and functional groups to assess relative resilience in complex systems. Ecosystems 8:958-966. http://dx.doi. org/10.1007/s10021-005-0147-X

Allen, C. R., and C. S. Holling. 2008. Discontinuities in ecosystems and other complex systems. Columbia University Press, New York, New York, USA.

Angeler, D. G., C. R. Allen, and R. K. Johnson. 2013a. Measuring the relative resilience of subarctic lakes to global change: redundancies of functions within and across temporal scales. Journal of Applied Ecology 50:572-584. http://dx.doi. org/10.1111/1365-2664.12092

Angeler, D. G., C. R. Allen, C. Rojo, M. Alvarez-Cobelas, M. A. Rodrigo, and S. Sánchez-Carrillo. 2013b. Inferring the relative resilience of alternative states. PLOS ONE 8(10):e77338. http:// dx.doi.org/10.1371/journal.pone.0077338

Angeler, D. G., S. Drakare, and R. K. Johnson. 2011. Revealing the organization of complex adaptive systems through multivariate time series modeling. Ecology and Society 16(3): 5. http://dx.doi.org/10.5751/ES-04175-160305

Angeler, D. G., and R. K. Johnson. 2012. Temporal scales and patterns of invertebrate biodiversity dynamics in boreal lakes recovering from acidification. Ecological Applications 22:1172-1186. http://dx.doi.org/10.1890/11-1474.1

Arscott, D. B., J. K. Jackson, and E. B. Kratzer. 2006. Role of rarity and taxonomic resolution in a regional and spatial analysis of stream macroinvertebrates. Journal of the North American Benthological Society 25:977-997. http://dx.doi.org/10.1899/0887-3593 (2006)025[0977:RORATR]2.0.CO;2

Baho, D. L., S. Drakare, R. K. Johnson, C. R. Allen, and D. G. Angeler. 2014. Similar resilience characteristics in lakes with different management practices. PLoS ONE 9(3):e91881. http:// dx.doi.org/10.1371/journal.pone.0091881

Balvanera, P., A. B. Pfisterer, N. Buchmann, J.-S. He, T. Nakashizuka, D. Raffaelli, and B. Schmid. 2006. Quantifying the evidence for biodiversity effects on ecosystem functioning and services. Ecology Letters 9:1146-1156. http://dx.doi.org/10.1111/ j.1461-0248.2006.00963.X

Bengtsson, J. 2010. Applied (meta)community ecology: diversity and ecosystem services at the intersection of local and regional processes. Pages 115-131 in H. A. Verhoef and P. J. Morin, editors. 
Community ecology: processes, models, and applications. Oxford University Press, New York, New York, USA. http://dx.doi. org/10.1093/acprof:oso/9780199228973.003.0010

Bogan, M. T., and D. A. Lytle. 2007. Seasonal flow variation allows 'time sharing' by disparate aquatic insect communities in montane desert streams. Freshwater Biology 52:290-304. http:// dx.doi.org/10.1111/j.1365-2427.2006.01691.X

Borcard, D., and P. Legendre. 2002. All-scale spatial analysis of ecological data by means of principal coordinates of neighbour matrices. Ecological Modelling 153:51-68. http://dx.doi. org/10.1016/S0304-3800(01)00501-4

Borcard, D., P. Legendre, C. Avois-Jacquet, and H. Tuomisto. 2004. Dissecting the spatial structure of ecological data at multiple scales. Ecology 85:1826-1832. http://dx.doi.org/10.1890/03-3111

Brown, B. L., and C. M. Swan. 2010. Dendritic network structure constrains metacommunity properties in riverine ecosystems. Journal of Animal Ecology 79:571-580. http://dx.doi.org/10.1111/ j.1365-2656.2010.01668.x

Brown, B. L., C. M. Swan, D. A. Auerbach, E. H. Campbell Grant, N. P. Hitt, K. O. Maloney, and C. Patrick. 2011. Metacommunity theory as a multispecies, multiscale framework for studying the influence of river network structure on riverine communities and ecosystems. Journal of the North American Benthological Society 30:310-327. http://dx.doi.org/10.1899/10-129.1

Buffam, I., H. Laudon, J. Temnerud, C.-M. Mörth, and K. Bishop. 2007. Landscape-scale variability of acidity and dissolved organic carbon during spring flood in a boreal stream network. Journal of Geophysical Research 112:G01022. http://dx.doi. org/10.1029/2006JG000218

Chapin, F. S., III, E. S. Zavaleta, V. T. Eviner, R. L. Naylor, P. M. Vitousek, H. L. Reynolds, D. U. Hooper, S. Lavorel, O. E. Sala, S. E. Hobbie, M. C. Mack, and S. Díaz. 2000. Consequences of changing biodiversity. Nature 405:234-242. http://dx.doi. org/10.1038/35012241

Clarke, A., R. Mac Nally, N. Bond, and P. S. Lake. 2008. Macroinvertebrate diversity in headwater streams: a review. Freshwater Biology 53:1707-1721. http://dx.doi.org/10.1111/ j.1365-2427.2008.02041.X

Cowell, B. C., A. H. Remley, and D. M. Lynch. 2004. Seasonal changes in the distribution and abundance of benthic invertebrates in six headwater streams in central Florida. Hydrobiologia 522:99-115. http://dx.doi.org/10.1023/B: HYDR.0000029977.94089.b8

Cumming, G. S. 2011. Spatial resilience in social-ecological systems. Springer, Dordrecht, The Netherlands. http://dx.doi. org/10.1007/978-94-007-0307-0

De Bie, T., L. De Meester, L. Brendonck, K. Martens, B. Goddeeris, D. Ercken, H. Hampel, L. Denys, L. Vanhecke, K. Van der Gucht, J. Van Wichelen, W. Vyverman, and S. A. J. Declerck. 2012. Body size and dispersal mode as key traits determining metacommunity structure of aquatic organisms. Ecology Letters 15:740-747. http://dx.doi.org/10.1111/ j.1461-0248.2012.01794.x
Declerck, S. A. J., J. S. Coronel, P. Legendre, and L. Brendonck. 2011. Scale dependency of processes structuring metacommunities of cladocerans in temporary pools of High-Andes wetlands. Ecography 34:296-305. http://dx.doi.org/10.1111/j.1600-0587.2010.06462. $\underline{x}$

Dray, S., P. Legendre, and F. G. Blanchet. 2009. Packfor: forward selection with permutation (Canoco p.46). $R$ package version 0.0-7/r58. The R Project for Statistical Computing, Vienna, Austria. [online] URL: http://r-forge.r-project.org/R/?group_id=195

Duarte, L. D. S., P. V. Prieto, and V. D. Pillar. 2012. Assessing spatial and environmental drivers of phylogenetic structure in Brazilian Araucaria forests. Ecography 35:952-960. http://dx. doi. org/10.1111/j.1600-0587.2011.07193.x

Ehrlich, P. R., and A. H. Ehrlich. 1981. Extinction: the causes and consequences of the disappearance of species. Ballantine Books, New York, New York, USA.

Elmqvist, T., C. Folke, M. Nyström, G. Peterson, J. Bengtsson, B. Walker, and J. Norberg. 2003. Response diversity, ecosystem change, and resilience. Frontiers in Ecology and the Environment 1:488-494. http://dx.doi.org/10.1890/1540-9295(2003)001[0488: RDECAR]2.0.CO;2

Erős, T., P. Sály, P. Takács, A. Specziár, and P. Bíró. 2012. Temporal variability in the spatial and environmental determinants of functional metacommunity organization - stream fish in a human-modified landscape. Freshwater Biology 57:1914-1928. http://dx.doi.org/10.1111/j.1365-2427.2012.02842.x

Finn, D. S., N. Bonada, C. Múrria, and J. M. Hughes. 2011. Small but mighty: headwaters are vital to stream network biodiversity at two levels of organization. Journal of the North American Benthological Society 30:963-980. http://dx.doi.org/10.1899/11-012.1

Fischer, J., D. B. Lindenmayer, S. P. Blomberg, R. MontagueDrake, A. Felton, and J. A. Stein. 2007. Functional richness and relative resilience of bird communities in regions with different land use intensities. Ecosystems 10:964-974. http://dx.doi. org/10.1007/s10021-007-9071-6

Fonseca, C. R., and G. Ganade. 2001. Species functional redundancy, random extinctions and the stability of ecosystems. Journal of Ecology 89:118-125. http://dx.doi.org/10.1046/ j.1365-2745.2001.00528.X

Forys, E. A., and C. R. Allen. 2002. Functional group change within and across scales following invasions and extinctions in the Everglades ecosystem. Ecosystems 5:339-347. http://dx.doi. org/10.1007/s10021-001-0078-0

Fox, J., and S. Weisberg. 2011. An $R$ companion to applied regression. Second edition. Sage, Thousand Oaks, California, USA. [online] URL: http://socserv.socsci.mcmaster.ca/jfox/ Books/Companion

Frissell, C. A., W. J. Liss, C. E. Warren, and M. D. Hurley. 1986. A hierarchical framework for stream habitat classification: viewing streams in a watershed context. Environmental Management 10:199-214. http://dx.doi.org/10.1007/BF01867358

Garmestani, A. S., C. R. Allen, and L. Gunderson. 2009. Panarchy: discontinuities reveal similarities in the dynamic system 
structure of ecological and social systems. Ecology and Society 14(1): 15. [online] URL: http://www.ecologyandsociety.org/ vol14/iss1/art15/

Giller, P. S., and B. Malmqvist. 1998. The biology of streams and rivers. Oxford University Press, New York, New York, USA.

Göthe, E., D. G. Angeler, and L. Sandin. 2013. Metacommunity structure in a small boreal stream network. Journal of Animal Ecology 82:449-458. http://dx.doi.org/10.1111/1365-2656.12004

Hammer, O., D. A. T. Harper, and P. D. Ryan. 2001. PAST: paleontological statistics software package for education and data analysis. Palaeontologia Electronica 4:1-9.

Heino, J. 2013. The importance of metacommunity ecology for environmental assessment research in the freshwater realm. Biological Reviews 88:166-178. http://dx.doi.org/10.1111/ j.1469-185X.2012.00244.X

Heino, J., M. Grönroos, J. Soininen, R. Virtanen, and T. Muotka. 2012. Context dependency and metacommunity structuring in boreal headwater streams. Oikos 121:537-544. http://dx.doi. org/10.1111/j.1600-0706.2011.19715.X

Heywood, V. H. 1995. Global biodiversity assessment. Cambridge University Press, Cambridge, United Kingdom.

Holling, C. S. 1973. Resilience and stability of ecological systems. Annual Review of Ecology and Systematics 4:1-23. http://dx.doi. org/10.1146/annurev.es.04.110173.000245

Holling, C. S. 1992. Cross-scale morphology, geometry, and dynamics of ecosystems. Ecological Monographs 62:447-502. http://dx.doi.org/10.2307/2937313

Landeiro, V. L., W. E. Magnusson, A. S. Melo, H. M. V. EspíritoSanto, and L. M. Bini. 2011. Spatial eigenfunction analyses in stream networks: do watercourse and overland distances produce different results? Freshwater Biology 56:1184-1192. http://dx.doi. org/10.1111/j.1365-2427.2010.02563.X

Laudon, H., and K. H. Bishop. 1999. Quantifying sources of acid neutralisation capacity depression during spring flood episodes in Northern Sweden. Environmental Pollution 105:427-435. http:// dx.doi.org/10.1016/S0269-7491(99)00036-6

Laudon, H., S. Köhler, and I. Buffam. 2004. Seasonal TOC export from seven boreal catchments in northern Sweden. Aquatic Sciences 66:223-230. http://dx.doi.org/10.1007/s00027-004-0700-2

Legendre, P., D. Borcard, G. Blanchet, and S. Dray. 2010. PCNM: MEM spatial eigenfunction and principal coordinate analyses. $R$ package version 2.1/r82. The R Project for Statistical Computing, Vienna, Austria. [online] URL: http://r-forge.r-project.org/R/? group id $=195$

Legendre, P., and E. D. Gallagher. 2001. Ecologically meaningful transformations for ordination of species data. Oecologia 129:271-280. http://dx.doi.org/10.1007/s004420100716

Lindo, Z., and N. N. Winchester. 2009. Spatial and environmental factors contributing to patterns in arboreal and terrestrial oribatid mite diversity across spatial scales. Oecologia 160:817-825. http://dx.doi.org/10.1007/s00442-009-1348-3
Lu, J., L. Jiang, L. Yu, and Q. Sun. 2011. Local factors determine plant community structure on closely neighbored islands. PLoS ONE 6:e19762. http://dx.doi.org/10.1371/journal.pone.0019762

Luck, G. W., G. C. Daily, and P. R. Ehrlich. 2003. Population diversity and ecosystem services. Trends in Ecology \& Evolution 18:331-336. http://dx.doi.org/10.1016/S0169-5347(03)00100-9

Merritt, R. W., and K. W. Cummins. 1996. An introduction to the aquatic insects of North America. Third edition. Kendall-Hunt, Dubuque, Iowa, USA.

Montgomery, D. R. 1999. Process domains and the river continuum. Journal of the American Water Resources Association 35:397-410. http://dx.doi.org/10.1111/j.1752-1688.1999.tb03598. $\underline{\mathrm{X}}$

Moog, O. 1995. Fauna aquatica austriaca. Wasserwirtschaftskataster, Bundesministerium fur Land- und Forstwirtschaft, Vienna, Austria.

Mykrä, H., J. Heino, and T. Muotka. 2007. Scale-related patterns in the spatial and environmental components of stream macroinvertebrate assemblage variation. Global Ecology and Biogeography 16:149-159. http://dx.doi.org/10.1111/

j.1466-8238.2006.00272.x

Nash, K. L., C. R. Allen, D. G. Angeler, C. Barichievy, T. Eason, A. S. Garmestani, N. A. J. Graham, D. Granholm, M. Knutson, R. J. Nelson, M. Nyström, C. A. Stow, and S. M. Sundstrom. 2014. Discontinuities, cross-scale patterns, and the organization of ecosystems. Ecology 95:654-667. http://dx.doi.org/10.1890/13-1315.1

Nyström, M., and C. Folke. 2001. Spatial resilience of coral reefs. Ecosystems 4:406-417. http://dx.doi.org/10.1007/s10021-001-0019. $\mathrm{y}$

Oksanen, J., F. G. Blanchet, R. Kindt, P. Legendre, P. R. Minchin, R. B. O'Hara, G. L. Simpson, P. Solymos, M. H. H. Stevens, and H. Wagner. 2013. Vegan: community ecology package. R package version 2.0-8. The R Project for Statistical Computing, Vienna, Austria. [online] URL: http://CRAN.R-project.org/package= vegan

Ottosson Löfvenius, M., M. Kluge, and T. Lundmark. 2003. Snow and soil frost depth in two types of shelterwood and a clear-cut area. Scandinavian Journal of Forest Research 18:54-63. http://dx. doi.org/10.1080/02827581.2003.10383138

Petersen, I., J. H. Winterbottom, S. Orton, N. Friberg, A. G. Hildrew, D. C. Spiers, and W. S. C. Gurney. 1999. Emergence and lateral dispersal of adult Plecoptera and Trichoptera from Broadstone Stream, UK. Freshwater Biology 42:401-416. http:// dx.doi.org/10.1046/j.1365-2427.1999.00466.x

Peterson G., C. R. Allen, and C. S. Holling. 1998. Ecological resilience, biodiversity, and scale. Ecosystems 1:6-18. http://dx. doi.org/10.1007/s100219900002

R Development Core Team. 2011. R: a language and environment for statistical computing. R Foundation for Statistical Computing, Vienna, Austria. [online] URL: http://www.R-project.org

Resh, V. H., L. A. Bêche, and E. P. McElravy. 2005. How common are rare taxa in long-term benthic macroinvertebrate surveys? 
Journal of the North American Benthological Society 24:976-989. http://dx.doi.org/10.1899/05-026.1

Resh, V. H., A. V. Brown, A. P. Covich, M. E. Gurtz, H. W. Li, G. W. Minshall, S. R. Reice, A. L. Sheldon, J. B. Wallace, and R. C. Wissmar. 1988. The role of disturbance in stream ecology. Journal of the North American Benthological Society 7:433-455. http://dx.doi.org/10.2307/1467300

Richardson, J. S., and R. J. Danehy. 2007. A synthesis of the ecology of headwater streams and their riparian zones in temperate forests. Forest Science 53:131-147.

Sala, O. E., F. S. Chapin III, J. J. Armesto, E. Berlow, J. Bloomfield, R. Dirzo, E. Huber-Sanwald, L. F. Huenneke, R. B. Jackson, A. Kinzig, R. Leemans, D. M. Lodge, H. A. Mooney, M. Oesterheld, N. L. Poff, M. T. Sykes, B. H. Walker, M. Walker, and D. H. Wall. 2000. Global biodiversity scenarios for the year 2100. Science 287:1770-1774. http://dx.doi.org/10.1126/science.287.5459.1770

Shaw, R. G., and T. Mitchell-Olds. 1993. ANOVA for unbalanced data: an overview. Ecology 74:1638-1645. http://dx.doi. org/10.2307/1939922

Siqueira, T., L. M. Bini, F. O. Roque, S. R. Marques Couceiro, S. Trivinho-Strixino, and K. Cottenie. 2012. Common and rare species respond to similar niche processes in macroinvertebrate metacommunities. Ecography 35:183-192. http://dx.doi.org/10.1111/ j.1600-0587.2011.06875.x

Stow, C., C. R. Allen, and A. S. Garmestani. 2007. Evaluating discontinuities in complex systems: toward quantitative measures of resilience. Ecology and Society 12(1): 26. [online] URL: http:// www.ecologyandsociety.org/vol12/iss1/art26/

Sundstrom, S. M., C. R. Allen, and C. Barichievy. 2012. Species, functional groups, and thresholds in ecological resilience. Conservation Biology 26:305-314. http://dx.doi.org/10.1111/ j.1523-1739.2011.01822.x

Townsend, C. R. 1989. The patch dynamics concept of stream community ecology. Journal of the North American Benthological Society 8:36-50. http://dx.doi.org/10.2307/1467400

Vannote, R. L., G. W. Minshall, K. W. Cummins, J. R. Sedell, and C. E. Cushing. 1980. River continuum concept. Canadian Journal of Fisheries and Aquatic Sciences 37:130-137. http://dx.doi. org/10.1139/f80-017

Walker, B., A. Kinzig, and J. Langridge. 1999. Plant attribute diversity, resilience, and ecosystem function: the nature and significance of dominant and minor species. Ecosystems 2:95-113. http://dx.doi.org/10.1007/s100219900062

Wallace, J. B., and J. R. Webster. 1996. The role of macroinvertebrates in stream ecosystem function. Annual Review of Entomology 41:115-139. http://dx.doi.org/10.1146/annurev. en.41.010196.000555

Wang, H., J. Meng, and M. Tenenhaus. 2010. Regression modelling analysis on compositional data. Pages 381-406 in V. Esposito Vinzi, W. W. Chin, J. Henseler, and H. Wang, editors. Handbook of partial least squares. Springer-Verlag, Berlin, Germany. http://dx.doi.org/10.1007/978-3-540-32827-8_18
Ward, J. V. 1989. The four-dimensional nature of lotic environments. Journal of the North American Benthological Society 8:2-8. http://dx.doi.org/10.2307/1467397

Wardwell, D. A., C. R. Allen, G. D. Peterson, and A. J. Tyre. 2008. A test of the cross-scale resilience model: functional richness in Mediterranean-climate ecosystems. Ecological Complexity 5:165-182. http://dx.doi.org/10.1016/j.ecocom.2007.11.001

Wolman, M. G. 1954. A method of sampling coarse river-bed material. Transactions American Geophysical Union 35:951-956. 